\title{
Algıllanan Sosyal Kaytarma Ölçeği - Tüirkçe Formu: Genç ve Yetişkin Sporcu Örnekleminde Geçerlik ve Güvenirliğin İncelenmesi
}

\section{Perceived Social Loafing Questionnaire - Turkish Form: A Validity and Reliability Study in a Sample of Youth and Adult Athletes}

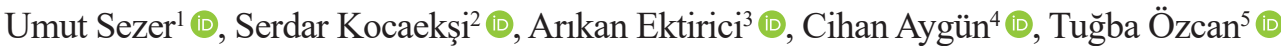

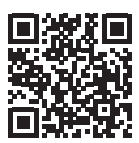

Yazar notu: Bu çalışmanın yetişkin örneklem bulguları 2018 yılında gerçekleştirilen IV. Uluslararası Egzersiz ve Spor Psikolojisi Kongresi'nde sözel olarak sunulmuştur.

${ }^{1}$ Araştırma Görevlisi, Eskişehir Teknik Üniversitesi Spor Bilimleri Fakültesi, Eskişehir - Türkiye

2Doçent Dr., Eskişehir Teknik Üniversitesi Spor Bilimleri Fakültesi, Eskişehir - Türkiye ${ }^{3}$ Araşstırma Görevlisi, Eskiş̧ehir Teknik Üniversitesi Spor Bilimleri Fakültesi, Eskişehir - Türkiye

${ }^{4}$ Araştırma Görevlisi, Eskişehir Teknik Üniversitesi Spor Bilimleri Fakültesi, Eskişehir - Türkiye

5Yüksek Lisans Öğrencisi, Anadolu

Üniversitesi Sağlik Bilimleri Enstitüsü,

Eskişehir, Türkiye

ORCID: U.S. 0000-0001-9764-0028;

S.K. 0000-0001-7176-7012;

S.K. $0000-0001-7176-7012 ;$
A.E. $0000-0002-1590-6687 ;$

C.Ä. 0000-0001-8773-8777;

Sorumlu yazar/Corresponding author: Umut Sezer,

Eskişehir Teknik Üniversitesi İki Eylül Kampüsü Gazipaşa Mh. Spor Bilimleri Fakültesi 26555, Eskişehir, Türkiye

E-posta/E-mail: umutsezer@eskisehir.edu.tr

Başvuru/Submitted: 05.10.2020 Revizyon Talebi/Revision Requested: 16.03.2021

Son Revizyon/Last Revision Received:

31.03.2021

Kabul/Accepted: 09.04.2021

Online Yayın/Published Online: 16.11.2021

Citation/Atıf: Sezer, U., Kocaekși, S., Ektirici, A., Aygün, C. ve Ozcan, T. (2021). Algılanan sosyal kaytarma ölçeği - Türkçe formu: Genc ve yetişkin sporcu ôrnekleminde geçerlik ve ve yetişkın sporcu ornekleminde geçerlik ve güvenirligin incelenmesi. Psikoloji çal

https://doi.org/10.26650/SP2020-805306
ÖZ

Sosyal kaytarma olgusu toplumdaki bireyler, sosyal kurumlar ve örgütler üzerindeki olumsuz etkilerinden ötürü "toplumsal bir hastalık" olarak nitelendirilmektedir. Bu çalışmada, Algılanan Sosyal Kaytarma Ölçeği (ASKÖ) Türkçe formunun genç ve yetişkin sporculardan oluşan örneklemlerde geçerlik ve güvenirlik bakımından incelenmesi amaçlanmıştır. Çalışmanın örneklemi, kolayda örnekleme yoluyla seçilen takım sporlarından (futbol, basketbol, voleybol, hentbol, rugby ve yüzme) genç ve yetişkin sporculardan oluşmaktadır. Örneklemin yetişkin grubu 201 (73 kadın ve 128 erkek; yaş Ort. $=21.59$, SS = 3.84), genç grubu ise 226 (107 kadın ve 119 erkek; yaş Ort. $=14.43, S S=$ 1.31) sporcuyu içermektedir. Ölçüm aracının yapı geçerliğini sınamak üzere doğrulayıcı faktör analizi uygulanmış, ortalama açıklanan varyans ve birleşik güvenirlik katsayılarıyla yakınsak geçerlik incelenmiş ve alanyazında belirtilen ilişkiler test edilmiştir. Ölçüm aracına ilişkin güvenirlik ise iç tutarlılık katsayısı, birleşik güvenirlik katsayısı ve madde-toplam korelasyonlarından faydalanılarak değerlendirilmiştir. Yapı geçerliği çerçevesinde gerçekleștirilen doğrulayıcı faktör analizinin bulguları orijinal ölçekteki tek boyutlu yapının her iki örneklemde de doğrulandığını göstermektedir. Ölçeğin yapı geçerliliğini desteklemek etmek üzere alanyazında belirtilen iliş̧iler (kolektif yeterlik ve algılanan sosyal kaytarma ilişkisi; takım sargınlığı ve algılanan sosyal kaytarma ilişkisi) test edilmiş ve ilişkilerin negatif yönde ve anlamlı olarak ortaya çıktığı görülmüştür. Yakınsak geçerliğe ilişkin değerlerin (AVE: ortalama açıklanan varyans ve CR: birleşik güvenirlik) istenilen düzeyde çıkması nedeniyle yakınsak geçerliğin sağlandığı değerlendirilmiştir. Ölçüm aracının her iki örneklemde de $($ Cronbach alfa yetişkin $=.79$; Cronbach alfa genç $=.77)$ iyi derecede güvenirlik değerlerine sahip olduğu anlaşılmıştır. Bu çalışmanın sonuçları, takımlarda sosyal kaytarma algısını ölçmek için kullanılan Algılanan Sosyal Kaytarma Ölçeği Türkçe formunun, genç ve yetişkin sporcularla gerçekleştirilecek çalışmalarda kullanılabilecek ölçüde güvenirlik ve geçerliğe sahip olduğunu göstermektedir. Anahtar Kelimeler: Algılanan Sosyal Kaytarma Ölçeği, sosyal kaytarma, algı, sporcu, motivasyon 


\section{ABSTRACT}

The phenomenon of social loafing can be described as a "social disease" due to its negative effects on individuals, social institutions, and organizations in society. This study aimed to examine the validity and reliability of the Turkish version of the Perceived Social Loafing Questionnaire (PSLQ) in the context of young and adult athletes. The participants of the study are composed of young and adult athletes from team sports (football, basketball, volleyball, handball, rugby, and swimming), who were recruited through convenience sampling. The adult participants consisted of 201 athletes ( 73 female and 128 male; $M_{\text {age }}=21.59$ years, $S D=3.84$ ), whereas the young participants consisted of 226 athletes (107 female and 119 male; $M_{\text {age }}=14.43$ years, $S D=1.31$ ). The Confirmatory Factor Analysis $(\mathrm{CFA})$ was applied to test the construct validity of the measure, the composite reliability (CR) and average variance extracted (AVE) were calculated to assess the convergence validity, and the correlations with other theoretically-related measures were calculated. Reliability tests included internal consistency coefficient (coefficient alpha), CR, and item-total correlations. The CFA results indicated that the model fits the data well in both participants. Construct validity was also evidenced through correlations with other theoretically-related variables (collective efficacy and perceived social loafing; team cohesion and perceived social loafing) with relationships being negative and significant. Satisfactory convergent validity was achieved through AVE and CR, with values exceeding the acceptable levels of convergence. The reliability coefficients of the measure were suitable for both participants (Cronbach's alpha adult $=0.79$; Cronbach's alpha young $=0.77$ ). This study demonstrates that the Turkish version of the PSLQ, which is used to measure the perception of social loafing in teams, has adequate evidence of reliability and validity to support its use in studies with young and adult athletes.

Keywords: Perceived Social Loafing Questionnaire, social loafing, perception, athletes, motivation

\section{EXTENDED ABSTRACT}

Social psychologists try to understand how social context impacts human behavior. Most studies within this framework reflect motivation gains when a person works as a group member (e.g., Köhler effect, social facilitation effect). Contrarily, social loafing, which was earlier termed the Ringelmann effect, is a social psychological phenomenon that is characterized by a reduction in effort and motivation due to the presence of other group members (Latane, Williams, \& Harkins, 1979). Research on social loafing has revealed that people expend less effort when working in groups than alone (Latané et al., 1979; Williams, Harkins, \& Latané, 1981). Perceived social loafing among group members can be detrimental to team performance, as individual motivation and performance strongly affect group effort (Mulvey \& Klein, 1998; Shepperd, 1993). Likewise, in sport, coordinated group effort leads to performance goals. Høigaard and his colleagues made a frequent contribution to the social loafing studies in team sports. Their work results supported the negative association between the social loafing tendency and some group concepts (i.e., team, cohesion, team identification, and collective efficacy) in team sports context (Høigaard, Boen, De Cuyper, \& Peters, 2013; Høigaard \& Peters, 2009; Høigaard, Säfvenbom, \& Tønnessen, 2006). Research shows that cultural orientations moderate the effects of social loafing, which means that the effect would be more significant for individualistic than collectivist societies (Earley, 1989, 1993; Erez \& Somech, 1996; Karau \& Williams, 1993). The Turkish culture has been described as collectivist, but individualistic orientations are rapidly increasing (Çileli, 2000; Hofstede, 
1980). Thus, social loafing is believed to have implications for Turkish athletes and coaches. This study aimed to explore the construct validity and reliability of the Perceived Social Loafing questionnaire (Høigaard, 2002; as cited in Høigaard et al., 2006) in young and adult athletes.

\section{Methods}

This study was carried out with two different participants; adult athletes ( $N=201,73$ female, $=21.39$ years, $S D=2.70 ; 128$ male $=21.70$ years, $S D=4.36)$ and young athletes $(N=226,107$ female, $=14.03$ years, $S D=1.11 ; 119$ male, $=14.79$ years, $S D=1.38)$ from team sports (football, basketball, volleyball, handball, rugby, and swimming). Athletes were recruited using convenience sampling with volunteer participants.

PSLQ (Høigaard, 2002; as cited in Høigaard et al., 2006) consists of 5-items rated on a 5-point Likert-type scale that measures social loafing perceptions in a team context. PSLQ was translated from English into Turkish with the back-translation method of Brislin (1986) and guidelines provided by Hambleton and Patsula (1999) to ensure cross-language validity of the scale. Descriptive statistics, Pearson correlation coefficient, confirmatory factor analyses, corrected item-total correlations, average variance extracted (AVE), composite reliability (CR), and internal consistency coefficient were used to determine the validity and reliability of the scale. Convergent validity was assessed using correlations with collective efficacy in the adult participants (Observational Collective Efficacy Scale for Sports; by Fransen, Kleinert, Dithurbide, Vanbeselaere, \& Boen, 2014) and team cohesion in the young participants (Youth Sport Environment Questionnaire; by Eys, Lougheed, Bray, \& Carron, 2009). The goodness-of-fit indexes (/df, TLI, GFI, CFI, RMSEA, SRMR) were examined.

\section{Results}

Confirmatory factor analyses indicated an excellent and good model fit to the data, respectively (Adult participants $/ \mathrm{df}=1.34, p>0.05$, Tucker-Lewis index $(\mathrm{TLI})=0.98$, Goodness-of-fit $(\mathrm{GFI})=0.98$, comparative fit index $(\mathrm{CFI})=0.99$, root mean square error of approximation $(\mathrm{RMSEA})=0.04$, standardized root mean square residual $(\mathrm{SRMR})=0.02$; Young participants $/ \mathrm{df}=02.12, p>.05, \mathrm{TLI}=0.96, \mathrm{GFI}=0.98, \mathrm{CFI}=0.99, \mathrm{RMSEA}=0.07, \mathrm{SRMR}=0.02$ ). Standardized factor loadings for adult and young participants ranged between 0.59 and 0.75 , and 0.51 and 0.75 , respectively. Correlation analyses showed negative and significant results with collective efficacy $(r[199]=-0.51, p<0.01)$, social cohesion $(r[224]=-0.29, p<$ $0.01)$, and task cohesion $(r[224]=-0.61, p<0.01)$. Corrected item-total correlations ranged between 0.54 and 0.63 for adults participants and 0.50 and 0.61 for young participants. The AVE and CR were calculated as 0.43 and 0.78 for adult participants and 0.41 and 0.77 for 
young participants, respectively. The internal consistency of the scale was 0.79 for the adult participants and 0.77 for the young participants.

\section{Discussion}

Confirmatory factor analyses verified the same factor structure, as in the original study, for both participants after modifications suggested by the Modification Indices. The goodnessof-fit indices revealed that the single-factor model was an excellent fit to data for adult and young athletes, respectively (Brown, 2015; Harrington, 2009; Hooper, Coughlan \& Mullen, 2008; Kline, 2005; Steiger, 1990; Tabachnick \& Fidell, 2007). Correlation analyses showed negative and significant results with collective efficacy and team cohesion dimensions, similar to the strength of relationships observed in the literature (Høigaard, Säfvenbom, \& Tønnessen, 2006; Mulvey \& Klein, 1998). The AVE was <0.5 for both participants; however, the $C R$ was above the recommended threshold of 0.6 , which indicates convergent validity of the PSLQ (Fornell \& Larcker, 1981). Corrected item-total correlations were above the minimum recommended level of 0.30 , which reflects the unprecedented power of the items (Büyüköztürk, 2013).

In conclusion, the Turkish form of the PSLQ appears to have adequate reliability and construct validity among young and adult athletes from team sports. Further studies should focus on measuring invariance across team sports, as group size is essential in social loafing research. 
Grupların bilişsel özellikleri ve bu çerçevede şekillenen grup davranışı kültürler arasinda farklılıklar gösterebilmektedir (Brewer ve Yuki, 2014; Yuki, 2003). Toplulukçu kültüre sahip toplumlarda sosyal davranış grup normlarına, toplum içindeki görev ve mecburiyetlere bağlı olarak ortaya çıkmaktadır. Bireyci kültürlerde ise birey en temel sosyal birim olarak otonom bir varlık şeklinde görülmekte, toplumsal birimler (aileler, gruplar ve organizasyonlar vb.) temelde bireylerin ihtiyaçlarını gidermek ve amaçlarına ulaşmalarını sağlamak üzere kullanılan bir araç olarak değerlendirilmektedir (Miller, 1994). Birbiriyle farklılaşan bu kültürel eğilimler motivasyon gibi çeşitli bireysel psikolojik örüntüler üzerinde etkili olmaktadır (Markus ve Kitayama, 1991). Bireyin grup içinde sahip olduğu motivasyonu ve gösterdiği çabayı olumsuz yönde etkileyen sosyal kaytarma olgusu, bireyler ve topluluklar üzerinde biraktığg etkiler nedeniyle "toplumsal bir hastalık" olarak nitelendirilmektedir (Latane, Williams ve Harkins, 1979). Grup içindeki sosyal kaytarma etkisi bireyci toplumlarda grup performansı ve üretkenlik bakımından önemli bir risk faktörüdür (Karau ve Williams, 1993; Karau ve Williams, 2001). Son yıllarda gerçekleştirilen araştırmalarla, sosyal kaytarmanın toplulukçu değerlere sahip ülkelerde de grup performansını olumsuz yönde etkilediği ortaya çıkmıştır (Byun, Karau, Dai ve Lee, 2018; Mefoh ve Nwanosike, 2012; Peng ve Lin, 2014; Ying, Li, Jiang, Peng ve Lin, 2014)

Genel anlamda toplulukçu kültürlerde gelişen bağıml1-ilişkisel benlik kurgusu ile bireyin sosyal sistemin bir parçası olarak uyum gösterdiği ve içinde bulunduğu grubun amaç ve ihtiyaçlarını daha fazla önemsediği görülmektedir (Markus ve Kitayama, 1991; Motti-Stefanidi, 2018; Triandis, 2001). Başarılı grup performansı için bireysel çaba gerektiren durumlarda kişi, toplulukçu kültürlerde içerisinde bulunduğu grubun çıkarına davranmayı kendi yararından üstün tutarken yüksek performans gösterme eğilimi sergilemekte; bireyci kültürlerde ise kendi yararını grup çıkarlarından daha önemli görmekte ve kendi performansı için verimli çalışmaya odaklanmaktadır (Earley, 1993; Kağıtçıbaşı ve Cemalc1lar, 2014). Genel anlamda toplulukçu kültürel özellikler sergilediği kabul edilen Türkiye'de grup içi toplulukçuluk (in-group collectivism) oldukça yüksektir (Pagda, Bayraktar ve Jimenez, 2021). Buna göre ülkemiz insanı, yakın çevrelerindeki gruplara sadakatle bağlanmakta, bu gruplarda yer aldıkları için onur duymakta ve onlara uyum göstermektedir (Dorfman, Javidan, Hanges, Dastmalchian ve House, 2012).

Türkiye, toplulukçu özellikleri baskın bir kültür olarak tanımlanıyor olsa da bireyci özelliklerin de giderek arttığ 1 vurgulanmaktadır (Çileli, 2000; Gürbüz ve Bingöl, 2007; 
Gürbüz ve Sığrı, 2012; Hofstede, 1980). Özellikle kent yaşamındaki sosyo-ekonomik şartların iyileşmesiyle aileyi ilgilendiren maddi konularda çocuk ve gençlerin katkılar1na olan ihtiyacın azalacağı ve özerkliğin ailenin maddi durumunu tehdit eden bir unsur olmaktan çıkacağı belirtilirken, bu değişimden ötürü ailelerin çocukların özerkliklerine daha fazla önem verecekleri ifade edilmektedir (Kağıtçıbaşı, 2007). Bu konuda yapılan çalışmalar ekonomik şartların iyileşmesiyle gençlerin benlik tanımlamalarının daha bireyci özellikler yansıttığını göstermektedir (İmamoğlu ve Karakitapoğlu-Aygün, 2004; Karakitapoğlu-Aygün ve İmamoğlu, 2002). Kağıtçıbaşı (2007), bireyci ve toplulukçu özelliklerin birlikte görüldüğü bu durumu "özerk-ilişkisel benlik" kurguysuyla açıklamıştır. Buna ek olarak Hofstede, Hofstede ve Minkov'un (2010) 93 ülkeyi bireyci özellikler açısından sıraladıkları raporda, Türkiye birçok toplulukçu ülkeden daha fazla bireyci bir ülke olarak değerlendirilmiş ve 37. sırada yer almıştır. Bu nedenle Türk kültürünü yalnızca toplulukçu bir yapıda ele almamak gerektiği, aynı zamanda bireyci ve toplulukçu özelliklerin bir arada görülebileceği ileri sürülmektedir (Aslan ve Güven, 2010; Kağıtçıbaş1, 2005; Morsünbül, Crocetti, Çok ve Meeus, 2016; Yetim, 2003). Alanyazındaki çalışmalar sosyal kaytarmanın, bireyci kültürlerdeki grup ortamında daha fazla görüldüğüne işaret etmektedir (Earley, 1989, 1993; Erez ve Somech, 1996; Karau ve Williams, 1993). Ülkemizde süregelen kültürel değişim ile bireyci özelliklerin ön plana çıkması, kişisel başarı ve kazanımları daha önemli hale getireceği ve bu durumun sosyal kaytarmanın görülme sıklığını arttıracağı öngörülmektedir.

Alan yazında sosyal kaytarmayı ölçmeye yarayan öz-bildirim ölçekleri mevcuttur (Høigaard, Fuglestad, Peters, Cuyper, Backer ve Boen, 2010; Schippers, 2014; Ying ve ark., 2014). Ancak değerlendirme süreçlerinde öz-bildirimsel yöntemlerin kullanılması katılımcılardan doğru ve geçerli veri elde etmeyi sosyal istenirlik ve sosyal onay gibi çeşitli süreçlerin etkisinden ötürü sınırlamaktadır (Adams ve ark., 2005). Bu nedenle algısal yöntemler kimi zaman değerlendirme açısından daha elverişli gözükmektedir. Høigaard (2002) tarafindan öne sürülen psikometrik anlamda güçlü algısal ölçüm arac1 ile takım içindeki olası sosyal kaytarma davranışları ölçülebilmektedir (Høigaard, Säfvenbom ve Tønnessen, 2006). Ayrıca, grup veya takım çalışması söz konusuyken kişinin yaşadığ 1 motivasyon kaybı genel olarak sosyal kaytarma olgusu çerçevesinde ele alınabilmektedir (Karau ve Wilhau, 2020). Sporda optimum düzeyde motivasyonun, yetenek gelişimi (Gagné, 2010; Issurin, 2017) ve başarılı performans (Durand-Bush ve Salmela, 2002; MacNamara, Button ve Collins, 2010; Singer ve Orbach, 1999) ile iliş- 
kilendirildiği düşünüldüğünde, grup veya takım ortamında yaşanacak motivasyon kayıpları, performans ve gelişim elde etmek üzere aşılması gereken bir sorun olarak görülmektedir. Dolayısıyla ülkemizde gerçekleştirilecek sosyal kaytarma araştırmalarında kullanılabilecek ölçüde geçerli ve güvenilir ölçüm araçlarına gereksinim söz konusudur. Bu çalışma çerçevesinde, sporcunun, takımdaki diğer üyelerin sergilediği sosyal kaytarma davranışlarına ilişkin algısını ölçmek üzere geliştirilen Algılanan Sosyal Kaytarma ölçeğinin Türk kültürüne uyarlanması, geçerlik ve güvenirlik çalışmalarının gerçekleştirilmesi amaçlanmıştır. Türkçeye kazandırılan ölçeğin, motivasyon eksikliği ve çaba düşüklüğü gibi konularda hizmet veren araştırmacı, antrenör ve spor psikolojisi uzmanları için bilgi sağlayacağı düşünülmektedir.

\section{Sosyal Kaytarma}

Sosyal psikoloji alan yazınındaki kavramlar, kültürel özelliklerin de tesiriyle grup ortamındaki sosyal eğilimleri düzenler ve dolayısıyla davranışsal süreçlerin sosyal temellerini etkilerler (Cross, Hardin ve Gercek-Swing, 2011). Bireyler, gruplarda kendine özgü dinamiklere sahip yaşayan bir sisteme dahil olurlar (Miller, 1976). Bu yaşayan sistem, üye etkileşimleri ile ortaya çıkan grup dinamikleri neticesinde değişip dönüşürken, üyeler ise bu sistemin kendine özgü niteliklerinden etkilenirler ya da özellikleriyle bu sistemi etkileyebilirler (Connors ve Caple, 2005). Zira, bu durum sosyal etkileşimlerin doğal bir sonucudur. Diğer yandan grup içerisinde yer alan bireylerin grubun görev bazlı davranış örüntülerini benimsemeleri, etkili grup davranışının sürdürülebilir ve uyumlu olması adına kaçınılmaz bir şarttır (Tschan, Semmer, Nägele ve Gurtner, 2000). Ancak, bireylerin grup ortamında yeterli düzeyde bireysel motivasyona sahip olmamaları istenilen çabayı göstermeme davranışıyla sonuçlanabilir. Dolayısıyla etkili grup davranışının beraberinde başarıyı getirdiği takım sporlarında, sporcuların motivasyonu ve çaba gösterme eğilimleri etkili grup davranışını gerçekleştirmek için önemli bir unsur halini almaktadır. Bunlar aslında sosyal kaytarmanın etkili olduğu çeşitli durumları vurgulamaktadır. Bu anlamda sosyal kaytarma, bireylerin motivasyon ve çaba gösterme eğilimlerini düzenleyen bir kavram olmakla birlikte, aynı zamanda etkili grup davranışı ve performans için bir risk faktörüdür (Karau ve Williams, 1993).

Sosyal kaytarma ilk defa Ringelmann tarafından incelenmiş, bireylerin grup içinde motivasyon ve çaba gösterme eğilimlerindeki olumsuz değişimi yansıtan bir kavram olarak tanımlanmıştır (Karau ve Williams, 1993; Kravitz ve Martin, 1986). Daha genel bir ifadeyle, görev yönelimli bir grubun üyesi olan bireyde görülen düşük motivasyon 
ile beraber bireysel çabasının azalmasıdır (Latane ve ark., 1979). Sosyal kaytarma eğilimi olan bireyin grup içindeki gerçek performansı ile kendisinden beklenen performans düzeyi arasında bir fark oluşur ve bu fark gruptaki kişi sayısında yükselme ile birlikte artar (Haugen, Reinboth, Hetlelid, Peters ve Høigaard, 2016). Yani grup büyüdükçe üyelerin sosyal kaytarma eğilimlerinin artması ve dolayısıyla bireysel çabalarının azalması olasıdır. Özellikle, yabancı bir ortamda çalışmakta olan, grubun hedefine ulaşması bakımından kendi performansını etkili görmeyen bireylerde, grup düzeyinde performansa dair standartlara sahip olmayan ve bireysel çıktıların açık bir şekilde değerlendirilmediği gruplarda görülmesi daha olasıdır (Haugen ve ark., 2016; Kellett, Humphrey ve Sleeth, 2000).

Alan yazındaki deneysel çalışmalar incelendiğinde, sosyal kaytarma eğiliminin genelde koaktif gruplar özelinde bağımlı değişken olarak ele alındığı (Karau ve Wilhau, 2020), kuramsal geçerliğin test edildiği (Høigaard ve ark., 2006; Liden, Wayne, Jaworski ve Bennet, 2004), ve sosyal kaytarma üzerinde etkili olan diğer süreçlerin anlaşılmaya çalışıldığı görülmektedir (Simms ve Nichols, 2014). Bu çalışmalar neticesinde sosyal kaytarmanın fiziksel, bilişsel ve algısal çaba gerektiren basit görevlerde bile ortaya çıkabileceği anlaşılmıştır (Heuzé ve Brunel, 2003). Sosyal kaytarma araştırmalarının odağ1 1990'lı yıllar ile birlikte laboratuvar ortamından saha çalışmalarına doğru kaymış ve böylelikle sosyal kaytarma etkisinin örgütsel yapılar içerisindeki doğal gruplar üzerinde de benzer örüntülere sahip olduğu anlaşılarak dış geçerlik ile ilgili soru işaretleri de giderilmiştir (George, 1992).

Sosyal kaytarma kavramı alanyazında bir dizi kuramsal yaklaşım çerçevesinde ele alınmıştır (Karau ve Wilhau, 2020). Bu kuramsal yaklaşımlar eskiden yeniye doğru beklenti-değer kuramı (Vroom, 1964), sosyal etki kuramı (Latané, 1981), çabanın gereksizliği (Kerr ve Bruun, 1983), heves azalması (Jackson ve Williams, 1985), değerlendirme potansiyeli (Harkins, 1987) ve ortaklaşa çaba modeli şeklindedir (Karau ve Williams, 1993). Bu yaklaşımlar içerisinde sosyal kaytarma olgusunu etkileyen faktörleri en geniş ölçüde ele alan yaklaşım ortaklaşa çaba modelidir. Bu model, 78 çalışmadan elde edilen değişken ve değişken kümelerinin sosyal kaytarma üzerindeki düzenleyici etkilerini ortaya koymuştur.

\section{Sporda Sosyal Kaytarma Çalışmaları}

Takım sporlarının yer aldığı müsabaka ortamları, başarı adına etkili grup davranışı gerektiren unsurları barındırır. Bu anlamdaki grup davranışı, birlikte çaba gerektiren 
(koaktif veya etkileşimli) süreçler sonucunda şekillenir. Koaktif sporlar çerçevesinde gerçekleştirilen deneysel çalışmalarda, sporcunun bireysel performansı temel gösterge (baseline) olarak alınarak takımca elde edilen performans ile karşılaştırılmakta ve böylelikle bireysel çabadaki gerçek düşüş bulunabilmektedir (Heuzé ve Brunel, 2003; Hüffmeier ve Hertel, 2011). Ancak temel göstergeden yoksun araştırmalarda performans değişimi ile gerçek bir veri ortaya koymak oldukça güç olduğundan, etkileşimsel takım sporlarında öz-bildirimsel ve algısal yöntemler kullanılmaktadır (Hüffmeier ve Hertel, 2020; Karau ve Wilhau, 2020). Bu bakımdan ölçüm yöntemleri farklılık gösterse de sosyal kaytarmanın gerek koaktif sporlarda (kürek, yüzme vs.) gerekse futbol ve hentbol gibi etkileşimli takım sporlarında benzer etkilere sahip olduğu görülmüştür (Høigaard ve ark., 2010; Høigaard ve Ommundsen, 2007; Swain, 1996). Görev yönelimli bir güdüsel iklim, yüksek görev sargınlığı, sporcunun takım içerisindeki rolünden hoşnut olması (Høigaard ve ark., 2010), yüksek kolektif yeterlik inancı (Høigaard ve Peters, 2009) ve takım ile kurulan özdeşimin yüksek olması sonucunda (Høigaard ve ark., 2013) sosyal kaytarmanın eğiliminin azalacağı ifade edilmektedir.

Koaktif spor dallarında sporcunun bireysel katkısı nesnel performans çıktıları (tur zamanı, mesafe vb.) ile somutlaştırılmaya çalışılsa da takım çalışması gerektiren etkileşimsel sporlarda sporcunun takımına yapmış olduğu katkı çeşitli teknolojik olanaklar ve bu olanaklar çerçevesinde sporcuların sıkı bir takibini gerektirmektedir (Høigaard ve Ingvaldsen, 2006; Jones, Høigaard ve Peters, 2014). Bu olanaklar sayesinde takım etkinliğine ilişkin elde edilecek parametreler sosyal kaytarma davranışlarını anlamak üzere kullanılabilecek veriler sağlayacaktır. Ancak bahsi geçen bu olanaklar genelde üst düzey takım sporlarında kullanıldığından alt seviyede (örn., genç veya amatör takımlar) bireysel motivasyon ve çaba için farklı yöntemlere ihtiyaç duyulmaktadır. Öz-bildirimsel ölçme araçları bu anlamda kullanılabilmektedir ancak katılımcılar bu araçlarla gerçekleştirilen çalışmalarda sosyal anlamda onaylanmayan cevaplar vermekten kaçınabilmektedirler (Ones, Viswesvaran ve Reiss, 1996). Üstelik rekabetçi spor ortamında, sporcu bireyler kendi sosyal kaytarma davranışlarını (motivasyon kaybı ve çaba eksikliği) kabul etmeyi de istemeyebilirler (Vaartstra, Dunn ve Causgrove Dunn, 2018). Algılanan sosyal kaytarma düzeyi ile gerçek sosyal kaytarma düzeyi arasındaki birlikte değişim sürekli aynı biçimde gerçekleşmese de takım arkadaşlarının çaba düzeyine dair olumsuz alg1 geliştiren sporcunun kendi motivasyonunu kaybetmesi ve bunun sonucunda takıma yönelik ilgi ve çabasının azalması muhtemeldir (Høigaard ve Ommundsen, 
2007; Mulvey, Bowes-Sperry ve Klein, 1998; Mulvey ve Klein, 1998; Schnake, 1991). Dolayısıyla takım arkadaşlarının sosyal kaytarma davranışları sergilediğini düşünen sporcu bireyde oluşacak bu olumsuz algı, sporcunun takım içinde göstereceği motivasyon, çaba ve performans ilişkisini olumsuz biçimde etkileyecektir. Üstelik bu olumsuz algının, sadece yarışma ortamında değil aynı zamanda antrenman ve benzeri diğer grup etkileşimleri gerektiren durumlarda da sosyal kaytarma davranışlarına yol açabileceği değerlendirilmektedir (Jones ve ark., 2014). Bu algının sonucunda oluşan olumsuz etki, takım potansiyelini arttırmak adına aşılması gereken bir önemli sorundur. Ayrıca böylesi bir algının grup etkileşimi ve dinamikleri üzerinde olumsuz rolü de söz konusudur. Genç futbolcular üzerinde gerçekleştirilen bir çalışmada, yüksek sosyal sargınlık, düşük görev sargınlığı ve grup normlarının sosyal kaytarmayı daha da arttıracağı ifade edilmektedir (Høigaard ve ark., 2006). Ayrıca takım içindeki güdüsel iklimin sosyal kaytarma üzerinde düzenleyici bir etkisinin olduğu Høigaard ve Ommundsen (2007) tarafindan ortaya konulmuştur. Bu nedenle takım içindeki sosyal kaytarma düzeyinin sporcuların algılarına başvurularak elde edilmesi geçerli bir yöntem olarak görülmektedir (Høigaard ve ark., 2006).

Çeşitli örneklemler üzerinde gerçekleştirilmiş çalışmalar sosyal kaytarma eğiliminin katılımcıların yaşları açısından farklılaştığını göstermektedir. Karau ve Williams'ın (1993) meta analiz çalışmasında çocuk, genç ve yetişkin katılımcılar arasında sosyal kaytarma eğilimi açısından anlamlı bir fark olduğu raporlanmıştır. Çalışmanın sonuçlarına göre, genç katılımcılar, çocuk ve yetişkinlerden daha fazla sosyal kaytarma eğilimi göstermektedir. Yazarlar genç ve çocuklar arasındaki bu eğilimi, belirli bir gelişim aşamasına gelmeden görev performansına yönelik stratejik davranışın görülemeyeceği ile açıklamışlar ancak örneklem çeşitliliği nedeniyle yetişkinler için bir çıkarımda bulunmamışlardır. Yazarların genç ve çocuklara yönelik ortaya koydukları bu düşünceyi sosyal karşılaştırma süreçleriyle desteklemek mümkündür. Buna göre, ergenliğin başlangıç evresinde çaba ve yeteneğe ilişkin çocukluktan farklı bir bakış açısı gelişmekte, böylelikle bireyin kendi yeteneklerini başkalarıyla karşılaştırması mümkün hale gelmektedir (Horn ve Weiss, 1991; Kipp, 2017). Gruptaki üyelerin kendilerine, diğer üyelere ve gruba yönelik algıları sosyal karşılaştırma süreçlerinden etkilenmekte ve dolayısıyla bu süreçler sosyal kaytarma üzerinde etkili olmaktadır (Comer, 1995). Sosyal karşılaştırmanın aynı zamanda performans ikliminin önemli bir unsuru olduğu (Ntoumanis ve Biddle, 1999), performans iklimi ile sosyal kaytarma arasında ise pozitif bir ilişkinin olduğu bi- 
linmektedir (De Backer, Boen, Cuyper, Høigaard ve Vande Broek, 2015; Høigaard ve Ommundsen 2007). Dolayısıyla gençlerde sosyal kaytarma algısı yalnızca motivasyon kaybı ve çaba düşüklüğü ile sonuçlanmamakta, aynı zamanda pozitif psiko-sosyal deneyimleri baskılayan takım dinamikleri de ortaya çıkarabilmektedir.

$\mathrm{Bu}$ çalışma çerçevesinde Türkçeye uyarlanan ASKÖ’nün, genç ve yetişkin sporcu örneklemlerinde yapısal geçerlik, yakınsak geçerlik, güvenirlik ve maddelerin ayırt edicilik düzeyi bakımından incelenmesi amaçlanmaktadır. Farklı kültürlerde ASKÖ ile gerçekleştirilen çalışma sayısı oldukça kısıtlıdır; bu sebeple bu çalışma alanyazına bu açıdan da katkı sağlayacaktır. Geçerlik çalışmaları kapsamında, yapısal geçerlik için doğrulayıcı faktör analizi (Kline, 2005), yakınsak geçerliğin test edilmesinde ise AVE (ortalama açıklanan varyans) ve CR (birleşik güvenirlik) değerleri (Fornell ve Larcker, 1981) kullanılmıştır. Bu çalışmadaki örneklemler üzerinde gerçekleştirilen DFA'dan elde edilen uyum iyiliği göstergelerinin ve yakınsak geçerliğe ilişkin elde edilen değerlerin kabul edilebilir düzeyde olması beklenmektedir. Yapısal geçerliğe kanıt sağlamak üzere ayrıca sosyal kaytarma algısının alanyazında belirtildiği şekilde kolektif yeterlik ve takım sargınlığı ile negatif bir ilişkiye sahip olması beklenmektedir (Høigaard ve Peters, 2009; Høigaard, Säfvenbom ve Tønnessen, 2006). Güvenirlik için hesaplanan iç tutarlılık katsayısı, CR katsayısı ve maddelerin ayırt edicilik düzeylerinin kabul edilebilir aralıklarda yer alması beklenmektedir. Bu çalışma kapsamında elde edilecek bulgulara yönelik ileri sürülen bu beklentilerin gerçekleşmesi ASKÖ’nün geçerlik ve güvenirliği için kanıt sağlayacaktır.

\section{YÖNTEM}

\section{Katılımelar}

Araştırmanın genç sporcu örneklemini Eskişehir ilinden kolayda örnekleme yöntemiyle belirlenen 81 futbolcu, 9 basketbolcu, 88 voleybolcu, 25 hentbolcu ve 23 yüzme sporcusu olmak üzere toplam 226 sporcu (Ort. yaş $=14.43$ ) oluşturmaktadır. Araştırmaya yaş ortalaması $14.03(S S=1.11)$ olan 107 kadın $(\% 47.3)$ ve yaş ortalaması $14.79(S S=$ 1.38) olan 119 erkek (\%52.7) katılmıştır. Araştırmanın katılımcılarının spor yaşı (sporculuk yaptıkları süre) ortalama 6 yıl $(S S=2.38)$; takımda bulunma süreleri ise 3.28 (SS $=2.08)$ yıldır.

Araştırmanın yetişkin sporcu örneklemini, Eskişehir ve Kastamonu illerinde spor hayatını sürdüren ve kolayda örnekleme yöntemi ile belirlenmiş 110 futbolcu, 15 bas- 
ketbolcu, 33 voleybolcu, 27 hentbolcu, 5 rugby ve 11 yüzme sporcusu olmak üzere 201 sporcu (Ort. yas $=21.59 ; S S=3.84)$ oluşturmaktadır. Yetişkin örneklemde yaş ortalaması 21.58 olan $(S S=2.66) 73$ kadın sporcu $(\% 36.3)$ ve yaş ortalaması $21.60(S S=4.34)$ olan 128 erkek sporcu (\%63.7) yer almaktadır. Yetişkin sporcuların ortalama spor yaşı $10.71(S S=4.61)$; takımda bulunma süreleri ise $2.86(S S=2.30)$ yıldır.

\section{Veri Toplama Aracı}

Algılanan Sosyal Kaytarma Ölçeği (ASKÖ). Algılanan Sosyal Kaytarma ölçeği, bireyin takım/grup içinde yer alan diğer üyelerin sosyal kaytarma davranışlarına yönelik algısını ölçmektedir (Bkz. Ek 1). Høigaard (2002) tarafından geliştirilen ölçek, 5'li Likert tipinde ( 1 = Hiç katılmıyorum, 5 = Tamamen katılıyorum) cevaplandırılmaktadır (akt. Høigaard ve ark., 2006). ASKÖ, tek boyut altında toplanan beş maddeye sahiptir. Maddeler, bireyin takım arkadaşlarına yönelik algıladığı sosyal kaytarma davranışlarını yansıtmaktadır. Ölçekten alınan yüksek puanlar, bireyin içinde bulunduğu takım ortamında algılamış olduğu sosyal kaytarma davranışlarının fazlalığına işaret etmektedir. Orijinal ölçeğin yapı geçerliğini test etmek üzere Temel Bileşenler Faktör Analizi uygulanmış ve ölçeğin tek faktörlü bir yapıya sahip olduğu anlaşılmıştır (Høigaard ve ark., 2006). Ölçüt bağıntılı geçerlik kapsamında gerçek kaytarma düzeyi ile algılanan kaytarma düzeyi arasındaki ortak değişim incelenmiştir (Høigaard ve Ingvaldsen, 2006). Bu değişimi incelemek üzere, iki deneysel koşul çerçevesinde performans ve çabayla ilgili nesnel ölçütlere yer verilen ve yer verilmeyen gruplar oluşturulmuştur. Sonuçlar, bu deneysel koşullar arasında algılanan sosyal kaytarmada anlamlı bir azalma [t (19) $=2.90$, $p<.005]$ olduğunu göstermiştir. Høigaard ve Ommundsen (2007) tarafindan gerçekleştirilen çalışmada orijinal formda yer alan maddelerin faktör yükleri .66 ila .75 arasında rapor edilmiştir. Ölçüm aracının kullanıldığı farklı çalışmalarda iç tutarlılık katsayısı .68 ile .75 aralığında raporlanmıştır (De Backer ve ark., 2015; Høigaard ve ark., 2006; Høigaard ve ark., 2010).

Sporda Gözlemsel Kolektif Yeterlik Ölçeği (SGKYÖ). ASKÖ’nün yetişkin sporcu örnekleminde yapısal geçerliğine kanıt sağlamak adına Sporda Gözlemsel Kolektif Yeterlik ölçeği (SGKYÖ) kullanılmıştır. Fransen, Kleinert, Dithurbide, Vanbeselaere ve Boen (2014) tarafından geliştirilmiş olan ölçek, kolektif yeterliğe ilişkin gözlemlenebilir prososyal davranışları içermekte ve kolektif yeterlik dinamiğini anlayabilmek için önemli bir araç olarak görülmektedir. Ölçek beş maddeden ve tek faktörden oluşan 7'li likert tipinde değerlendirilen bir ölçüm aracıdır. Orijinal ölçeğin iç tutarlılık (Alfa) kat- 
sayısı .85'tir. Ölçeğin Türkçe uyarlamasını Sezer, Kocaekşi, Taşcığlu, Özbal ve Heper (2020) gerçekleştirmiştir. Türkçe formdaki tek faktörlü yapı toplam varyansın \%57'sini açıklamaktadır. İlgili çalışmanın alfa katsayısı .79, birleşik güvenirlik katsayısı ise (CR) .78 olarak bulunmuştur (Sezer ve ark., 2020). Bu çalışma çerçevesinde SGKYÖ’nün iç tutarlı̆̆ 1.78 olarak hesaplanmıştır.

Genç Sporcu Takım Sargınlığı Ölçeği (GSTSÖ). Genç sporcu örnekleminde yapısal geçerliğe kanıt sağlamak üzere Genç Sporcu Takım Sargınlığı ölçeği (GSTSÖ) kullanılmıştır. GSTSÖ Eys, Lougheed, Bray ve Carron (2009) tarafından genç sporcu bağlamında takım sargınlığını ölçmek üzere geliştirilmiştir. Ölçek, sosyal sargınlık ve görev sargınlığ 1 olmak üzere iki faktöre dağılan 16 madde ile geçersiz verileri tespit etmek üzere değerlendirilen iki olumsuz maddeden oluşmakta ve 9'lu likert tipinde değerlendirilmektedir. Ölçekte yer alan iki faktörlü yapı toplam varyansın \%62'sini açıklamaktadır. Orjinal çalışmadaki iç tutarlılık katsayısı sosyal sargınlık için .94, görev sargınlığ 1 için ise .89’dur. Ölçek Türk kültürüne Sezer ve Kocaekşi (2018) tarafından uyarlanmıştır. Uyarlama çalışmasında GSTSÖ’nün genel iç tutarlığı .89, sosyal sargınlık ve görev sargınlık boyutlarının iç tutarlılığı ise .87'dir. CR katsayısı ölçeğin geneli için .93 , ölçek içerisinde yer alan iki faktör için ise .87 olarak bulunmuştur (Sezer ve Kocaekşi, 2018). Mevcut çalışmanın iç tutarlılık katsayısı sosyal sargınlık için .89, görev sargınlığı için ise .86 olarak elde edilmiştir.

\section{İșlem}

Uyarlama sürecinin ilk aşamasında orijinal çalışmayı gerçekleştiren araştırmacıya e-posta yolu ile ulaşılmış ve Haziran 2017 itibariyle uyarlama için gereken izinler alınmıştır. Çevirisi aşamasında Hambleton ve Patsula (1999) tarafindan belirtilen kültürlerarası ölçek uyarlamaya yönelik öneriler dikkate alınırken, çeviri aşamasında Brislin’in (1986) çeviri-geri çeviri yöntemine ilişkin olarak önerdiği çeviri adımları izlenmiş ve uzman görüşüne başvurulmuştur. Ölçeğin orijinal formu spor psikolojisi alanından iki uzmana ve bir İngiliz dil bilimci akademisyene gönderilerek Türkçeye çevrilmiştir. Üç uzmandan edinilen çeviriler araştırma ekibince değerlendirilmiş ve anlamsal bakımdan birbirleriyle en uyumlu çevirilere karar verilerek tek form haline getirilmiştir. Form, Türkçeye geri çeviri için ilk çeviri aşamasında yer alan uzmanlardan farklı iki dil bilimci akademisyene gönderilmiş, orijinal İngilizce form ve çeviri süreci sonrası elde edilen Türkçe form arasında anlamsal karşılaştırma yapılmıştır. Bu aşamadan sonra Türkçe forma ilişkin uzman görüşü alınmış ve uzman görüşü doğrultusunda son düzenlemeler 
gerçekleştirilmiştir. İki ölçek arasındaki dilsel eşdeğerliğin (anlam ve anlaşılırlık) yeterli seviyede olduğuna karar verilmesi sonucunda ASKÖ son halini almıştır.

Araştırmanın çeviri süreci gerçekleştirildikten sonra uygulamaya geçilmiştir. Yetişkin örneklemdeki araştırma verileri Şubat-Mart 2018 tarih aralığında ASKÖ, SGKYÖ ve kişisel bilgi formu aracıllğıyla antrenmanlar öncesinde toplanmıştır. Genç sporcu örneklemin verileri Aralık 2019-Ocak 2020 tarihleri arasında ASKÖ, GSTSÖ ve kişisel bilgi formu kullanılarak toplanmış ve uygulama antrenmanlar öncesinde gerçekleştirilmiştir.

Araştırma için Eskişehir Teknik Üniversitesi Sosyal ve Beşeri Bilimler Bilimsel Araştırma ve Yayın Etiği Kurulu'ndan gerekli etik izin alınmış (dosya no: 22126, 11 Kasım 2019) ve araştırma Helsinki Bildirgesindeki temel etik kurallara bağlı kalınarak gerçekleştirilmiştir. Veri toplama işlemi öncesinde araştırmanın yalnızca akademik amaçlarla gerçekleştirileceği, kişisel bilgilerin korunacağı ve elde edilen verilerin gizli kalacağına dair bilgilendirme yapılmıştır. Bu aşamanın ardından onam formları dağıtılarak araştırmaya katılan sporcuların gönüllü katılımı onaylaması gerektiği vurgulanmıştır. Böylelikle araştırmaya katılımın gönüllülük esasıyla olması sağlanmış ve araştırmada yer almak istemeyen sporcular uygulamanın dışında tutulmuştur. Veriler araştırmacı ve katılımcıların yüz yüze olduğu bir ortamda toplanmıştır.

\section{Verilerin Analizi}

Araştırma verileri betimleyici istatistikler, korelasyon analizi, doğrulayıcı faktör analizi (DFA), düzeltilmiş madde-toplam korelâsyonları, ortalama açıklanan varyans (AVE) değeri, iç tutarlık ve birleşik güvenirlik (CR) katsayısı yöntemlerinden yararlanılarak analiz edilmiştir. Analizler için SPSS 24 ve AMOS 24 istatistik programları kullanılmıştır.

Modelin verilerle uyumunu test etmek için DFA gerçekleştirilmiştir. Alanyazında model-veri uyumu için kullanılan ki kare/serbestlik derecesi, TLI, GFI, CFI, RMSEA ve SRMR göstergelerinin mükemmel düzeydeki uyum referansları temel alınmıştır (Kline, 2005). Buna göre, ki kare/serbestlik derecesi değerinin 3’ten küçük; TLI değerinin .95 ve üzeri (Harrington, 2009); GFI değerinin 90 ve üzeri (Hooper, Coughlan ve Mullen, 2008); CFI değerinin .90 ve üzeri (Tabachnick ve Fidell, 2007); RMSEA değerinin .07 'nin altında (Steiger, 1990) ve SRMR değerinin ise .08'in altında (Brown, 2015) olması beklenmektedir. 
Ölçme aracına ilişkin yakınsak geçerliğinin test edilmesinde AVE değeri ve CR katsayısı kullanılmıştır. Yakınsak geçerliğin sağlanabilmesi için AVE ve CR değerlerinin, alanyazındaki sınır değerler olarak kabul edilen .5 (AVE) ve .6'nın (CR) üzerinde, AVE değerinin .5'in altında kalması durumunda ise CR değerinin .6'nın üzerinde olması gerektiği belirtilmektedir (Fornell ve Larcker, 1981; Gefen, Straub ve Boudreau, 2000; Hair, Black, Babin ve Anderson, 2010). Ölçeğin yapısal geçerliğine kanıt sağlamak üzere alanyazında belirtilen ve aralarında ilişki olması beklenen diğer ölçeklerle korelasyonları hesaplanmıştır. Ölçüm aracında yer alan maddelere ilişkin standardize faktör yükleri (Lambda-X), maddelerin ayırt edicilik düzeyleri için düzeltilmiş madde-toplam korelasyonları ve ölçeğin güvenirliğini değerlendirmek üzere iç tutarlılık katsayısı (Cronbach Alfa) hesaplanmıştır.

\section{BULGULAR}

\section{Doğrulayıcı Faktör Analizi}

Orijinal ölçekteki faktör yapısını genç ve yetişkin sporculardan oluşan örneklemlerde sınamak için DFA gerçekleştirilmiştir. DFA, ölçekte yer alan maddelerin ilgili faktörlerle uyumunu test etmeye yarayan analiz tekniğidir (Field, 2005). DFA sonucunda elde edilen uyum iyiliği göstergeleri Tablo 1'de sunulmuştur.

Tablo 1. Doğrulayıcı Faktör Analizine İlişkin Uyum İyiliği Göstergeleri

\begin{tabular}{llccccccc}
\hline Model & İndeks & $\boldsymbol{s} \boldsymbol{d}$ & $\boldsymbol{p}$ & TLI & GFI & CFI & RMSEA & SRMR \\
\hline \multirow{2}{*}{ Yetişkin } & Modifikasyon Öncesi & 2.61 & $.02 *$ & .94 & .97 & .97 & .09 & .03 \\
& Modifikasyon Sonrası & 1.34 & .25 & .98 & .98 & .99 & .04 & .02 \\
\multirow{2}{*}{ Genç } & Modifikasyon Öncesi & 11.31 & $.00 *$ & .68 & .90 & .84 & .21 & .07 \\
& Modifikasyon Sonrası & 2.12 & .09 & .96 & .98 & .99 & .07 & .02 \\
\hline
\end{tabular}

${ }^{*} p<.05$, sd: serbestlik derecesi, TLI: Tucker-Lewis Index, GFI: Uyum İyiliği İndeksi, CFI: Karşılaştırmalı Uyum İndeksi, RMSEA: Yaklaşık Hataların Ortalama Karekökü, SRMR: Standardize Edilmiş Artık Ortalamaların Karekökü

Tablo 1 incelendiğinde, uyum iyiliği göstergelerinin alanyazında belirtilen kabul edilebilir sınır değerlerin altında kaldığı görülmektedir. Yetişkin örneklemde gerçekleştirilen ilk DFA sonucunda yaklaşık hataların ortalama karekökü (RMSEA) değerinin istenilen düzeyde olmadığı ve ki kare değerinin anlamlı düzeyde olduğu görüldüğünden modifikasyon indisleri incelenmiştir. Ölçme aracında yer alan maddelerde olumlu ve olumsuz ifadelerin birlikte kullanılması, ters puanlanan maddelere yer verilmesi gibi ifadeleştirme ile ilgili durumlar hata varyansına neden olabilmektedir (Goodboy ve Martin, 2020; Harrington, 2009). Modifikasyon indisleri tarafından önerilen hata kovar- 
yansı eşleştirmelerinde ilgili maddelerin ifadeleştirme bakımından benzer örüntülere sahip olduğu değerlendirildiğinden madde 2 ile madde 5 arasındaki yüksek modifikasyon değerine sahip hata kovaryansları eşleştirilmiş ve analiz tekrarlanmıştır. Modifikasyon sonrası elde edilen ki kare değerinin anlamsız olduğu ve uyum iyiliği göstergelerinin mükemmel uyum ölçütlerini karşıladığ 1 görülmüştür. Genç sporcu örnekleminde ise madde 1-4 ve madde 2-4 arasında benzer bir işlem gerçekleştirilmiş ve uyum iyiliği göstergeleri iyi uyum ölçütlerini karşılamıştır.

ASKÖ'de yer alan maddelere ilişkin faktör yükleri yetişkin sporcu örneklemi için .59 ile .75 arasında, genç sporcu örneklemi için ise .51 ile .75 arasında değişmektedir (Bkz. Tablo 3). Elde edilen bu değerler faktör yüklerine ilişkin olarak önerilen .5 değerinin üzerindedir. Buradan hareketle her iki örneklem çerçevesinde ileri düzeyde model-veri uyumu elde edilirken, ASKÖ’nün orijinal ölçekteki tek faktörlü yapıyı desteklediği ve iyi düzeyde faktör yüklerine sahip olduğu ortaya çıkmaktadır.

ASKÖ'nün yakınsak geçerliği CR, AVE ve diğer ölçeklerle olan korelasyonları arac1lığıyla incelenmiştir. Yakınsak geçerliğe ilişkin elde edilen değerler, yetişkin sporcu örnekleminde $\mathrm{AVE}=.43$ ve $\mathrm{CR}=.78$ olarak, genç sporcu örneklemde ise $\mathrm{AVE}=.41$ ve $\mathrm{CR}=.77$ olarak hesaplanmıştır. AVE değerinin .5'in altında ve CR değerinin .6'nın üzerinde olması yakınsama geçerliliği için yeterli düzeyde kanıt sunmaktadır.

ASKÖ’nün yapısal geçerliğine kanıt sağlamak üzere yetişkin sporcu örnekleminde gözlemsel kolektif yeterlik ile genç sporcu örnekleminde ise takım sargınlığının boyutları ile olan ilişkisine bakılmıştır (Bkz. Tablo 2). ASKÖ, yetişkin sporcu örnekleminde kullanılan SGKYÖ ile .51 düzeyinde negatif, genç sporcu örnekleminde kullanılan GSTSÖ-S ile .29 ve GSTSÖ-G ile ise .61 düzeyinde negatif ilişkilere sahiptir. İlgili değerler ve ilişkilerden hareketle yapısal geçerliğe ilişkin ilave kanıtlara ulaşıldığı görülmüştür.

Tablo 2. ASKÖ’nün Diğer Ölçeklerle İlişkisine Yönelik Korelasyon Katsayıları

\begin{tabular}{|c|c|c|c|}
\hline & $\begin{array}{l}\text { SGKYÖ } \\
(N=201)\end{array}$ & $\begin{array}{c}\text { GSTSÖ-S } \\
(N=\mathbf{2 2 6})\end{array}$ & $\begin{array}{c}\text { GSTSÖ-G } \\
(N=\mathbf{2 2 6})\end{array}$ \\
\hline ASKÖ & $-.52 *$ & $-.29 *$ & $-.62 *$ \\
\hline
\end{tabular}




\section{Madde ve Güvenirlik Analizi}

Ölçekte yer alan maddelerin ölçeğin tamamına yönelik temsil gücünü ortaya koymak üzere madde-toplam korelasyonlarından yararlanılmıştır. Madde analizi sonucunda yetişkin örneklemde düzeltilmiş madde-toplam korelasyonlarından en düşüğünün .55, en yüksek korelasyonun ise .63; genç örneklemde ise .50 ve .61 olduğu görülmüş, alt ve üst dilimlere yönelik gerçekleştirilen $t$ testi her iki örneklemde de anlamlı çıkmıştır $\left(\mathrm{t}_{\text {yetiş- }}\right.$ kin $\left.(127)=27.74, p<001 ; \mathrm{t}_{\text {genç }}(146)=30.54, p<001\right)$. ASKÖ içerisinde yer alan maddelere yönelik ayrıca açıklanan varyans değeri (çoklu korelasyon kareleri) hesaplanmıştır. Maddelere ilişkin elde edilen açıklanan varyans değerleri yetişkin sporcu örneklemide .35 ile .55 arasında, genç sporcu örnekleminde ise .25 ile .56 arasında hesaplanmıştır.

Ölçeğin güvenirliğini ortaya koymak üzere kullanılan Alfa katsayısı yetişkin örneklemde .79, genç örneklemde ise .77 olarak hesaplanmıştır. DFA'dan türetilmiş bir diğer güvenirlik katsayısı olan CR değeri yetişkin sporcu örneklemi için .78, genç sporcu örneklemi için ise .77'dir.

Her iki sporcu örneklemi üzerinde gerçekleştirilen DFA sonucunda elde edilen faktör yükleri, $R^{2}$ ve $t$ değerleri ile düzeltilmiş madde-toplam korelasyonları ve iç tutarlılık katsayıları Tablo 3’te verilmiştir.

Tablo 3. DFA Sonucunda Elde Edilen Faktör Yükleri, $\mathrm{R}^{2}$ ve t değerleri, DMTC ve Alfa Katsayıları

\begin{tabular}{|c|c|c|c|c|c|c|c|c|}
\hline Model & Madde & Ort. & $S S$ & Lambda- $X$ & $R^{2}$ & $t$ & DMTC & Cronbach's $\alpha$ \\
\hline \multirow{5}{*}{ Yetişkin } & 1 & 1.84 & .89 & .67 & .43 & $6.76^{*}$ & .55 & \multirow{5}{*}{.79} \\
\hline & 2 & 1.68 & 1.07 & .59 & .35 & $6.64 *$ & .57 & \\
\hline & 3 & 2.23 & 1.32 & .75 & .55 & $7.84 *$ & .63 & \\
\hline & 4 & 1.85 & 1.00 & .66 & .46 & $7.49 *$ & .57 & \\
\hline & 5 & 1.93 & 1.24 & .60 & .36 & $6.76^{*}$ & .58 & \\
\hline \multirow{5}{*}{ Genç } & 1 & 1.63 & .94 & .51 & .25 & $6.24 *$ & .55 & \multirow{5}{*}{.77} \\
\hline & 2 & 1.59 & 1.08 & .66 & .43 & $5.94 *$ & .50 & \\
\hline & 3 & 1.96 & 1.29 & .60 & .35 & $5.79 *$ & .54 & \\
\hline & 4 & 1.66 & .95 & .68 & .45 & $8.23^{*}$ & .61 & \\
\hline & 5 & 1.75 & 1.20 & .75 & .56 & $6.24 *$ & .60 & \\
\hline
\end{tabular}

* $p<.001$, DMTC: Düzeltilmiş Madde-Toplam Korelasyonu

\section{TARTIŞMA}

$\mathrm{Bu}$ çalışma çerçevesinde Algılanan Sosyal Kaytarma ölçeği (Høigaard, 2002, Akt: Høigaard ve ark., 2006) Türkçeye uyarlanmış, yetişkin ve genç sporcuların yer aldığ takım sporları bağlamında ölçeğin psikometrik özelliklerinin incelenmesi amaçlanmış- 
tır. Bu çalışmanın sonuçları dahilinde, ASKÖ'nün tek faktörlü yapısını hem yetişkin hem de genç Türk sporcular bağlamında destekleyen kanıtlara ulaşılmış ve ölçme aracının kabul edilebilir düzeyde iç tutarlılık gösterdiği anlaşılmıştır. Bu bulgular, orijinal ölçeğe ilişkin yapı geçerliğinin incelendiği çalışmalarda elde edilen bulgularla benzerlik göstermektedir (Høigaard ve ark., 2006; Høigaard ve Ingvaldsen, 2006; Høigaard ve Ommundsen, 2007).

ASKÖ’nün yapı geçerliğini sınamak üzere DFA uygulanmış ve alanyazında belirtilen ilişkilere yönelik korelasyon analizi gerçekleştirilmiştir. Modifikasyon sonucunda yetişkin sporcu örnekleminde elde edilen değerler mükemmel uyum ölçütlerini; genç sporcu örnekleminde ise kabul edilebilir uyum ölçütlerini karşılamaktadır. Yapısal geçerlik için ASKÖ ile takım sargınlığı algısı ve kolektif yeterlik inancı ilişkilerine bakılmıştır. Diğer bir ifadeyle, yüksek düzeylerde kolektif yeterlik inancı ve takım sargınlığı algısına sahip sporcularda algılanan sosyal kaytarma düzeyinin düşük olması beklenmektedir (Høigaard ve ark., 2010; Mulvey ve Klein, 1998). Gerçekleştirilen korelasyon analizinin sonuçlarına göre algılanan sosyal kaytarma; genç sporcu örnekleminde sosyal sargınlık faktörü ile düşük düzeyde, görev sargınlığı faktörü ile orta düzeyde negatif ve anlamlı ilişkilere sahip olarak bulgulanmıştır. Yetişkin sporcu örnekleminde ise kolektif yeterlik inancı ile algılanan sosyal kaytarma arasında orta düzeyde negatif yönlü ve anlamlı bir ilişki söz konusudur. ASKÖ ile her iki yapı arasında negatif yönlü anlamlı ilişkiler gözlemlendiğinden elde edilen sonuçlar alanyazında belirtilen ilişkileri desteklemektedir (Høigaard ve Peters, 2009; Høigaard ve ark., 2006). Dolayısıyla bu bulgular ölçeğin yapı geçerliğini destekler niteliktedir.

Ölçeğin güvenirliğine yönelik olarak iç tutarlılık katsayısı, birleşik güvenirlik katsayısı ve madde-toplam korelasyonları hesaplanmıştır. ASKÖ için hesaplanan Cronbach Alfa ve birleşik güvenirlik katsayıları kabul edilebilir düzeyler arasında ortaya çıkmıştır (Field, 2005; Fornell ve Larcker, 1981). Güvenirliğe ilişkin elde edilen bu bulgular ölçeğin kullanıldığı farklı çalışmalardaki iç tutarlılık bulgularıyla benzeşmektedir (De Backer ve ark., 2015; Høigaard ve ark., 2006; Høigaard ve ark., 2010). Gerçekleştirilen madde analizi sonuçları maddelerin genel yapıyı temsil etme derecelerinin kabul edilebilir olduğunu göstermektedir. Bunun yanı sıra her maddeye yönelik açıklanan varyans değeri (çoklu korelasyon kareleri) istenilen eşiğin üzerinde ve anlamlı olarak elde edilmiştir (Hair ve ark., 2010). 
Öz-bildirimsel yöntemler aracılığıyla sporcuların sosyal kaytarma düzeylerine ilişkin doğru bilgi elde etmenin (sosyal istenirlik ve sosyal onay gibi sebeplerden dolayi) güç bir durum olduğu düşünüldüğünde, takım içerisinde algılanan sosyal kaytarma düzeyini ölçmesi ve yansıtması için geliştirilen ASKÖ, bu durumun ötesine geçmek için iyi bir alternatif olarak görülmektedir (Mulvey ve Klein, 1998). Ancak unutulmamalıdır ki, sosyal kaytarma algısı takım içinde gerçek bir kaytarmacı olmadan da oluşabilmektedir. Bu nedenle sosyal kaytarma algısı ile mevcut sosyal kaytarma davranışı ve ortaya konulan çaba düzeyi arasında her zaman bir ilişki olmayabileceği ifade edilmektedir (Karau ve Williams, 1993; Mulvey ve Klein, 1998). Buna rağmen, takım içinde gerçekten kaytaran birileri olmadığında bile sosyal kaytarma algısı sporcularda motivasyon kaybına yol açıp takım için olumsuz sonuçlar doğurabilmektedir (Høigaard ve Ommundsen, 2007).

Sosyal kaytarma algısına yönelik örgütsel iş grupları, spor takımları ve proje gruplar1 gibi örneklemler üzerinde gerçekleştirilen çok sayıda araştırma mevcuttur (örn., Karau ve Wilhau, 2020). Son y1llarda ülkemizde gerçekleştirilen sosyal kaytarma çalışmaları artış gösterirken çalışmalar genelde iş grupları üzerine odaklanmıştır (örn., Kafes ve Kaya, 2017). Türkçe alanyazında sportif bağlam içerisinde gerçekleştirilmiş sosyal kaytarma araştırmaları Tolukan, Bayrak ve Karacan Doğan'ın (2017) çalışması ile sınırlıdır. Araştırmada antrenörlerin çalışma arkadaşlarına yönelik algılamış oldukları sosyal kaytarma davranışları çeşitli değişkenler aracılığıyla incelenmiştir. ASKÖ, özellikle sporcular üzerinde kullanılan bir ölçek olmakla birlikte, farklı kültürlerde sosyal kaytarma algısının ölçümünde kullanılan benzer ölçekler de mevcuttur (George, 1992; Jassawalla, Sashittal ve Sashittal, 2009; Liden ve ark., 2004; Mulvey ve Klein, 1998; Ying ve ark., 2014). Toplulukçu kültür bağlamında ASKÖ ile yapılan tek çalışma, sosyal kaytarma algısının grup performansı üzerindeki etkisini ortaya koymak üzere gerçekleştirilen Ying ve arkadaşlarının (2014) çalışmasıdır. Ancak söz konusu çalışmada ölçeğin psikometrik özellikleri ve uyarlama sürecine ilişkin bilgi sunulmamıştır. $\mathrm{Bu}$ nedenle mevcut çalışmada geçerlik ve güvenirlik bakımından elde edilen kanıtların, toplulukçu kültürel değer sistemine sahip ülkelere yönelik önemli çıkarımlar sağlayacağ1 düşünülmektedir.

Deneyimli, uzmanlık geliştirmiş veya yüksek bireysel beceri sahibi sporcularda sosyal kaytarmanın görülme sıklığının daha düşük olduğu görülmektedir (Anshel, 1995; Czyz, Szmajke, Kruger ve Kübler, 2016; Hardy ve Crace, 1991). Özellikle son zaman- 
larda genç sporcuların spor aktivitelerinde pozitif psikososyal deneyimlerin öne çıkması (Evans ve ark., 2017) ve sportif faaliyetlerde uzmanlaşmak için zamana ihtiyaç duydukları göz önüne alındığında, genç sporcu gruplarında sosyal kaytarma etkisine yönelik gerçekleştirilecek çalışmalar oldukça önem taşımaktadır. Zira takım sporlarını tanımlayan temel unsurlar rekabet ve kazanma vurgusu gibi olgulardır. Bu olguların genç sporcu gruplarında 1srarla öne çıkarılması sonucunda spora katılım motivasyonu düşebilmekte ve spordan kopma davranışları görülebilmektedir (Kassing ve ark., 2004; Lee, 2020). Rekabet ve kazanma vurgusu aynı zamanda performans odaklı bir güdüsel iklimin unsurları olarak görülmektedir (Harwood ve Thrower, 2020). Høigaard ve Ommundsen (2007) genç sporcularla gerçekleştirdikleri çalışmada, performans odaklı bir güdüsel iklimde bireysel performans için tanımlanabilir ölçütler kullanılmadığında algılanan sosyal kaytarmanın yükseleceğini ortaya koymuşlardır. Dolayısıyla pozitif psikososyal deneyimlerden (örn., spordan keyif almak, başkalarıyla bağ kurmak, sosyal destek sağlamak) yoksun ve performansa odaklanan bir takım ortamında sosyal kaytarma ve spordan kopma davranışlarının görülmesi olasıdır. Potansiyel vadeden yetenekli sporcuların böylesi durumlar sonucunda yaşadıkları motivasyon kayıpları ve spordan kopuşları, sosyal kaytarma olgusunun bu bağlam içerisinde araştırılması gerektiğine dair inancımızı pekiştirmektedir. Dolayısıyla ASKÖ'nün, hem genç hem de yetişkin sporcular bağlamında planlama, gözlem ve değerlendirme boyutlarında antrenörler ve uygulamada çalışan psikolojik destek uzmanları ve diğer bilim insanları için faydalı parametreler sağlayacağına inanılmaktadır.

Sosyal kaytarmanın kültürümüzde yarattığı etkiyi değerlendirmek üzere gelecek çalışmalara ışık tutacağı düşünülen bu araştırma bazı sınırlılıklara sahiptir. İlk olarak, çalışmanın verileri kolayda örnekleme yöntemi ile kesitsel olarak toplandığından sonuçlar genellenebilirlik bakımından sınırlıdır. Araştırmaya hem etkileşimsel hem de koaktif spor dallarından sporcular katılmıştır. Ancak, spor dallarına ilişkin katılımcı sayısının görece düşük olması sebebiyle, mevcut çalışmada yer alan spor dallarına veya sporun türüne özgü ölçüm değişmezliğinin değerlendirilebilmesi adına bir karşılaştırma yapılamamıştır. Bu nedenle farklı spor dallarında ölçüm değişmezliği üzerine gerçekleştirilecek çalışmaların toplulukçu kültürler açısından faydalı olacağı düşünülmektedir. İkinci olarak, bu çalışmada ölçeğin güvenirliği bakımından iç tutarlılık ve birleşik güvenirlik katsayıları hesaplanmış ve madde analizi gerçekleştirilmiştir. Gelecek çalışmalarda ASKÖ’nün cinsiyetler açısından karşılaştırılması, test-tekrar test güvenirliğinin incelenme- 
si ve bireysel çaba ile yakınsaklığının değerlendirilmesi önerilmektedir. Ayrıca yetişkinlerle gerçekleştirilen sosyal kaytarma araştırmalarından elde edilen çalışma sonuçlarının, genç sporcular bağlamında tekrarlanabilirliği ile ilgili çalışmalar gerçekleştirilebilir. Bunun yanında antrenman ve hazırlık gibi süreçlerde sosyal kaytarmanın varlığına yönelik araştırmalar önem taşımaktadır (Bkz. preloafing, Ohlert ve Kleinert, 2012). Dolayısıyla boylamsal olarak toplanacak veriler aracılığıyla sosyal kaytarma algısındaki dalgalanmaların incelenmesi gerektiği düşünülmektedir.

Sonuç olarak bu çalışma ile farklı bir kültürel bağlamda geliştirilmiş ve sosyal kaytarma olgusuna yönelik yakınsak bir gösterge ortaya koyan ASKÖ’nün, toplulukçu özellikleri ağır basan kültürümüzde takım sporları bağlamında kullanılabilecek ölçüde iyi psikometrik özelliklere sahip olduğu anlaşılmıştır. Bu sebeple ASKÖ’nün, sosyal kaytarma ve motivasyon kaybına yönelik gelecekte yapılacak çalışmalarda kullanılması önerilmektedir.

Etik Komite Onayı: Araştırma için Eskişehir Teknik Üniversitesi Sosyal ve Beşeri Bilimler Bilimsel Araştırma ve Yayın Etiği Kurulu'ndan gerekli etik izin alınmış (dosya no: 22126, 11 Kasım 2019) ve araştırma Helsinki Bildirgesindeki temel etik kurallara bağlı kalınarak gerçekleştirilmiştir.

Hakem Değerlendirmesi: Dış bağımsız.

Yazar Katkıları: Çalışma Konsepti/Tasarım- U.S.; Veri Toplama- U.S., S.K., A.E., C.A., T.Ö.; Veri Analizi/YorumlamaU.S., S.K; Yazı Taslağı- U.S.; İçeriğin Eleştirel İncelemesi- U.S., S.K., A.E., C.A., T.Ö.; Son Onay ve Sorumluluk- U.S. Çıkar Çatışması: Yazarlar çıkar çatışması bildirmemiştir.

Finansal Destek: Yazarlar bu çalışma için finansal destek almadığını beyan etmiştir.

Ethics Committee Approval: For the research, the necessary ethical permission was obtained from the Social and Human Sciences Scientific Research and Publication Ethics Committee of Eskişehir Technical University (file no: 22126, 11 November 2019) and the research was carried out in accordance with the basic ethical rules in the Declaration of Helsinki.

Peer-review: Externally peer-reviewed.

Author Contributions: Conception/Design of Study- U.S.; Data Acquisition- U.S., S.K., A.E., C.A., T.Ö.; Data Analysis/Interpretation- U.S., S.K.; Drafting Manuscript- U.S.; Critical Revision of Manuscript- U.S., S.K., A.E., C.A., T.Ö.; Final Approval and Accountability- U.S.

Conflict of Interest: The authors have no conflict of interest to declare.

Grant Support: The authors declared that this study has received no financial support.

\section{References/Kaynakça}

Adams, S. A., Matthews, C. E., Ebbeling, C. B., Moore, C. G., Cunningham, J. E., Fulton, J. ve Hebert, J. R. (2005). The effect of social desirability and social approval on self-reports of physical activity. American Journal of Epidemiology, 161(4), 389-398. https://doi.org/10.1093/aje/kwi054

Anshel, M. H. (1995). Examining social loafing among elite female rowers as a function of task duration and mood. Journal of Sport Behavior, 18(1), 39-49. 
Aslan, S. ve Güven, M. (2010). Bağlanma ve kişisel uyum arasındaki ilişkide ayrışma bireyleşmenin aracılığı. Eğitim ve Bilim, 35(157).

Brewer, M. B. ve Yuki, M. (2014). Culture and group processes: Defining the interface. M. Yuki ve M. Brewer (Ed.), Culture and group processes içinde (s. 1-14). New York, NY: Oxford University Press.

Brislin, R.W. (1986). The wording and translation of research instruments. W. J. Lonner ve J. W. Berry (Ed.), Field methods in cross-cultural research içinde (s. 137-164). Beverly Hills: Sage.

Brown, T. A. (2015). Confirmatory factor analysis for applied research (2. bask1). New York, NY: Guilford Publications.

Büyüköztürk, Ş. (2013). Sosyal bilimler için veri analizi el kitabı (14. bask1). Pegem Yayınevi, Ankara. Byun, G., Karau, S. J., Dai, Y. ve Lee, S. (2018). A three-level examination of the cascading effects of ethical leadership on employee outcomes: A moderated mediation analysis. Journal of Business Research, 88, 44-53. https://doi.org/10.1016/j.jbusres.2018.03.004

Comer, D. R. (1995). A model of social loafing in real work groups. Human Relations, 48(6), 647-667. https://doi.org/10.1177/001872679504800603

Connors, J. V. ve Caple, R. B. (2005). A review of group systems theory. The Journal for Specialists in Group Work, 30(2), 93-110. https://doi.org/10.1080/01933920590925940

Cross, S. E., Hardin, E. E. ve Gercek-Swing, B. (2011). The what, how, why, and where of self-construal. Personality and Social Psychology Review, 15(2), 142-179. https://doi. org $/ 10.1177 / 1088868310373752$

Czyz, S. H., Szmajke, A., Kruger, A. ve Kübler, M. (2016). Participation in team sports can eliminate the effect of social loafing. Perceptual and Motor Skills, 123(3), 754-768. https://doi. org $/ 10.1177 / 0031512516664938$

Çileli, M. (2000). Change in value orientations of Turkish youth from 1989 to 1995. The Journal of Psychology, 134(3), 297-305. https://doi.org/10.1080/00223980009600869

De Backer, M., Boen, F., De Cuyper, B., Høigaard, R. ve Vande Broek, G. (2015). A team fares well with a fair coach: Predictors of social loafing in interactive female sport teams. Scandinavian Journal of Medicine \& Science in Sports, 25(6), 897-908. https://doi.org/10.1111/sms.12303

Dorfman, P., M. Javidan, P. Hanges, A. Dastmalchian ve House R. (2012). "GLOBE: A Twenty Year Journey into the Intriguing World of Culture and Leadership" Journal of World Business, 47(4), 504-518. https://doi.org/10.1080/10413200290103473

Durand-Bush, N. ve Salmela, J. H. (2002). The development and maintenance of expert athletic performance: Perceptions of world and Olympic champions. Journal of Applied Sport Psychology, 14(3), 154-171.

Earley, P. C. (1989). Social loafing and collectivism: A comparison of the United States and the People's Republic of China. Administrative Science Quarterly, 34(4), 565-581. https://doi. org/10.2307/2393567

Earley, P. C. (1993). East meets west meets mideast: Further explorations of collectivistic and individualistic work groups. Academy of Management Journal, 36(2), 319-348. https://doi. org/10.5465/256525

Erez, M. ve Somech, A. (1996). Is group productivity loss the rule or the exception? Effects of culture and group-based motivation. Academy of Management Journal, 39(6), 1513-1537. https://doi. org/10.5465/257067

Evans, M. B., Allan, V., Erickson, K., Martin, L. J., Budziszewski, R. ve Côté, J. (2017). Are all sport activities equal? A systematic review of how youth psychosocial experiences vary across differing sport activities. British Journal of Sports Medicine, 51(3), 169-176.

Eys, M., Loughead, T., Bray, S. R. ve Carron, A. V. (2009). Development of a cohesion questionnaire for youth: The Youth Sport Environment Questionnaire. Journal of Sport and Exercise Psychology, 31(3), 390-408. https://doi.org/10.1123/jsep.31.3.390 
Field, A. (2005). Discovering statistics using SPSS (2. bs). London: Sage.

Fornell, C. ve Larcker, D. F. (1981). Evaluating structural equation models with unobservable variables and measurement error. Journal of Marketing Research, 18, 39-50. https://doi. org $/ 10.1177 / 002224378101800104$

Fransen, K., Kleinert, J., Dithurbide, L., Vanbeselaere, N. ve Boen, F. (2014). Collective efficacy or team outcome confidence? Development and validation of the Observational Collective Efficacy Scale for Sports (OCESS). International Journal of Sport Psychology, 45(2), 121-137. https://doi. org/10.7352/IJSP.2014.45.121

Gagné, F. (2010). Motivation within the DMGT 2.0 framework. High Ability Studies, 21(2), 81-99.

Gefen, D., Straub, D. W. ve Boudreau, M. (2000). Structural equation modeling techniques and regression: guidelines for research practice. Communications of the Association for Information Systems, 4(1), 1-78. https://doi.org/10.17705/1CAIS.00407

George, J. M. (1992). Extrinsic and intrinsic origins of perceived social loafing in organizations. Academy of Management Journal, 35(1), 191-202. https://doi.org/10.5465/256478

Goodboy, A. K. ve Martin, M. M. (2020). Omega over alpha for reliability estimation of unidimensional communication measures. Annals of the International Communication Association, 44(4), 422-439. https://doi.org/10.1080/23808985.2020.1846135

Gürbüz, S. ve Bingöl, D. (2007). Çeşitli örgüt yöneticilerinin güç mesafesi, belirsizlikten kaçınma, eril-dişil ve bireyci-toplulukçu kültür boyutlarına yönelik eğilimleri üzerine görgül bir araştırma. Savunma Bilimleri Dergisi, 6(2), 68-87.

Gürbüz, S. ve Sığrı, Ü. (2012, Mayıs). Kariyer çapalarının, temel benlik değerlendirmesi ve kültürel değerler ile ilişsisi: Türkiye ve ABD karşılaştırmast. 20. Ulusal Yönetim ve Organizasyon Kongresi’nde sunulan bildiri. Dokuz Eylül Üniversitesi, İzmir.

Hair, J. F., Black, W. C., Babin, B. J. ve Anderson, R. E. (2010). Multivariate data analysis: A global perspective (7. bs). Upper saddle River, NJ: Pearson.

Hambleton, R. K. ve Patsula, L. (1999). Increasing the validity of adapted tests: Myths to be avoided and guidelines for improving test adaptation practices. Journal of Applied Testing Technology, 1(1), $1-16$.

Hardy, C. J. ve Crace, R. K. (1991). The effects of task structure and teammate competence on social loafing. Journal of Sport and Exercise Psychology, 13(4), 372-381.

Harkins, S. (1987). Social loafing and social facilitation. Journal of Experimental Social Psychology, $23,1-18$.

Harrington, D. (2009). Confirmatory factor analysis. New York: Oxford University.

Harwood, C. G. ve Thrower, S. N. (2020). Motivational climate in youth sport groups. M.W. Bruner, M.A. Eys ve L.J. Martin (Ed.), The power of groups in youth sport içinde (s. 145-163). Elsevier BV: Amsterdam.

Haugen, T., Reinboth, M., Hetlelid, K. J., Peters, D. M. ve Høigaard, R. (2016). Mental toughness moderates social loafing in cycle time-trial performance. Research Quarterly for Exercise and Sport, 87(3), 305-310. https://doi.org/10.1080/02701367.2016.1149144

Heuzé, J. P. ve Brunel, P. C. (2003). Social loafing in a competitive context. International Journal of Sport and Exercise Psychology, 1(3), 246-263. https://doi.org/10.1080/1612197X.2003.9671717

Hofstede, G. (1980). Culture's Consequences: International Differences in Work-Related Values. Newbury Park, CA: Sage.

Hofstede, G., Hofstede, G. J. ve Minkov, M. (2010). Cultures and organizations: Software of the mind: Intercultural cooperation and its importance for survival. London: McGraw-Hill. 
Horn, T.S. ve Weiss, M. R. (1991). A developmental analysis of children's self-ability judgements in the physical domain. Pediatric Exercise Science, 3, 312-328.

Høigaard, R. (2002). Perceived social loafing questionnaire (Yayınlanmamış makale). Agder University College, Kristiansand.

Høigaard, R. ve Ingvaldsen, R. P. (2006). Social loafing in interactive groups: The effects of identifiability on effort and individual performance in floorball. Athletic Insight, 8(2), 52-63.

Høigaard, R. ve Ommundsen, Y. (2007). Perceived social loafing and anticipated effort reduction among young football (soccer) players: An achievement goal perspective. Psychological Reports, 100(3), 857-875. https://doi.org/10.2466/pr0.100.3.857-875

Høigaard, R. ve Peters, D. M. (2009, Haziran). The contribution of group cohesion and collective efficacy to perceived social loafing in football teams. XII. Uluslararası Spor Psikolojisi Derneği Dünya Kongresi'nde sunulan bildiri, Marrakesh, Morocco.

Høigaard, R., Boen, F., De Cuyper, B. ve Peters, D. M. (2013). Team identification reduces social loafing and promotes social laboring in cycling. International Journal of Applied Sports Science, 25, 33-40.

Høigaard, R., Fuglestad, S., Peters, D. M., Cuyper, B. D., Backer, M. D. ve Boen, F. (2010). Role satisfaction mediates the relation between role ambiguity and social loafing among elite women handball players. Journal of Applied Sport Psychology, 22(4), 408-419. https://doi.org/10.1080/10 413200.2010 .495326

Høigaard, R., Säfvenbom, R. ve Tønnessen, F. E. (2006). The relationship between group cohesion, group norms, and perceived social loafing in soccer teams. Small Group Research, 37(3), 217-232. https://doi.org/10.1177/1046496406287311

Hooper, D., Coughlan, J. ve Mullen, M. (2008). Structural equation modeling: Guidelines for determining model fit. The Electronic Journal of Business Research Methods, 6(1), 53- 60.

Hüffmeier, J. ve Hertel, G. (2020). Effort losses and effort gains in sports teams. Steven J. Karau (Ed.), Individual motivation within groups içinde (s. 109-148). New York: Academic Press.

Hüffmeier, J. ve Hertel, G. (2011). Many cheers make light the work: How social support triggers process gains in teams. Journal of Managerial Psychology, 26, 185-204. http://dx.doi. org/10.1108/02683941111112631

İmamoğlu, E. O. ve Karakitapoğlu-Aygün, Z. (2004). Self-construals and values in different cultural and socioeconomic contexts. Genetic, Social, and General Psychology Monographs, 130(4), $277-$ 306. https://doi.org/10.3200/MONO.130.4.277-306

Issurin, V. B. (2017). Evidence-based prerequisites and precursors of athletic talent: A review. Sports Medicine, 47(10), 1993-2010.

Jackson, J. M. ve Williams, K. D. (1985). Social loafing on difficult tasks: Working collectively can improve performance. Journal of Personality and Social Psychology, 49, 937-942.

Jassawalla, A., Sashittal, H. ve Sashittal, A. (2009). Students' perceptions of social loafing: Its antecedents and consequences in undergraduate business classroom teams. Academy of Management Learning \& Education, 8(1), 42-54. https://doi.org/10.5465/amle.2009.37012178

Jones, G. W., Høigaard, R. ve Peters, D. M. (2014). "Just going through the motions....": A qualitative exploration of athlete perceptions of social loafing in training and competition contextsimplications for team sport coaches. International Journal of Sports Science \& Coaching, 9(5), 1067-1082. https://doi.org/10.1260/1747-9541.9.5.1067

Kafes, M. ve Kaya, Ş. D. (2017). Sosyal kaytarma davranışı üzerine yapılmış çalışmaların incelenmesi. Türk \& İslam Dünyası Sosyal Araştırmalar Dergisi, 11, 227-245. 
Kağıtçıbaşı, Ç. (2005). Autonomy and relatedness in cultural context: Implications for self and family. Journal of Cross-cultural Psychology, 36(4), 403-422. https://doi.org/10.1177/0022022105275959

Kağıtçıbaşı, Ç. (2007). Family, Self, and Human Development Across Cultures, Theory and Applications (2. Bask1). London: Lawrence Erlbaum Associates.

Kağıtçıbaşı, Ç. ve Cemalcılar, Z. (2014). Dünden bugüne insan ve insanlar: Sosyal psikolojiye giriş. Istanbul: Evrim Yayınları.

Karakitapoğlu-Aygün, Z. ve İmamoĝlu, E. O. (2002). Value domains of Turkish adults and university students. The Journal of Social Psychology, 142(3), 333-351. https://doi. org/10.1080/00224540209603903

Karau, S. J. ve Wilhau, A. J. (2020). Social loafing and motivation gains in groups: An integrative review. Steven J. Karau (Ed.), Individual motivation within groups içinde (s. 3-51). New York: Academic Press.

Karau, S. J. ve Williams, K. D. (1993). Social loafing: A meta-analytic review and theoretical integration. Journal of Personality and Social Psychology, 65(4), 681- 706. https://doi.org/10.1037/0022-3514.65.4.681

Karau, S. J. ve Williams, K. D. (2001). Understanding individual motivation in groups: The collective effort model. M.E. Turner (Ed.), Groups at work: Theory and research içinde (s. 113-141). Mahwah, NJ: Lawrence Erlbaum Associates.

Kellett, J. B., Humphrey, R. H. ve Sleeth, R. G. (2000). We're great” vs.“you're lazy": How goal difficulty influences social loafing, collective efficacy and perceived team ability. Annual meeting of the Southern Management Association kongresinde sunulan bildiri, Orlando, Florida.

Kerr, N. L. ve Bruun, S. (1983). The dispensability of member effort and group motivation losses: Free rider effects. Journal of Personality and Social Psychology, 44, 78-94.

Kipp, L. E. (2017). Developmental considerations for working with young athletes. C. J. Knight, C. G. Harwood ve D. Gould (Editörler), Sport psychology for young athletes içinde (s. 32-42). London, UK: Routledge.

Kline, R. B. (2005). Principles and practice of Structural Equation Modeling (2. bs). New York: The Guilford Press.

Kravitz, D. A. ve Martin, B. (1986). Ringelmann rediscovered: The original article. Journal of Personality and Social Psychology, 50(5), 936-941. https://doi.org/10.1037/0022- 3514.50.5.936

Kassing, J. W., Billings, A. C., Brown, R. S., Halone, K. K., Harrison, K., Krizek, B., Mean, L.J. ve Turman, P. D. (2004). Communication in the community of sport: The process of enacting, (re) producing, consuming, and organizing sport. Annals of the International Communication Association, 28(1), 373-409. https://doi.org/10.1080/23808985.2004.11679040

Latané, B. (1981). The psychology of social impact. American Psychologist, 36, 343-356.

Latané, B., Williams, K. ve Harkins, S. (1979). Many hands make light the work: The causes and consequences of social loafing. Journal of Personality and Social Psychology, 37(6), 822. https:// doi.org/10.1037/0022-3514.37.6.822

Lee, Y. H. (2020). The role of mindfulness and occupational stress in the goal orientations of development and winning. Sport Management Review, 23(4), 626-639.

Liden, R. C., Wayne, S. J., Jaworski, R. A. ve Bennett, N. (2004). Social loafing: A field investigation. Journal of Management, 30(2), 285-304.

MacNamara, Á., Button, A. ve Collins, D. (2010). The role of psychological characteristics in facilitating the pathway to elite performance part 1: Identifying mental skills and behaviors. The Sport Psychologist, 24(1), 52-73. 
Markus, H. R. ve Kitayama, S. (1991). Culture and the self: Implications for cognition, emotion, and motivation. Psychological Review, 98(2), 224.

Mefoh, P. C. ve Nwanosike, C. L. (2012). Effects of group size and expectancy of reward on social loafing. IFE PsychologIA: An International Journal, 20(1), 229-240.

Miller, J. G. (1976). The nature of living systems. Behavioral Science, 21(5), 295-319.

Miller, J. G. (1994). Cultural diversity in the morality of caring: Individually oriented versus duty-based interpersonal moral codes. Cross-Cultural Research, 28(1), 3-39.

Morsünbül, U., Crocetti, E., Çok, F. ve Meeus, W. (2016). Identity statuses and psychosocial functioning in Turkish youth: A person-centered approach. Journal of Adolescence, 47, 145-155.

Motti-Stefanidi, F. (2018). Resilience among immigrant youth: The role of culture, development and acculturation. Developmental Review, 50, 99-109. https://doi.org/10.1016/j.dr.2018.04.002

Mulvey, P. W. ve Klein, H. J. (1998). The impact of perceived loafing and collective efficacy on group goal processes and group performance. Organizational Behavior and Human Decision Processes, 74(1), 62-87. https://doi.org/10.1006/obhd.1998.2753

Mulvey, P. W., Bowes-Sperry, L. ve Klein, H. J. (1998). The effects of perceived loafing and defensive impression management on group effectiveness. Small Group Research, 29(3), 394-415. https://doi. org $/ 10.1177 / 1046496498293006$

Ntoumanis, N. ve Biddle, S. J. (1999). A review of motivational climate in physical activity. Journal of Sports Sciences, 17(8), 643-665.

Ohlert, J. ve Kleinert, J. (2012). Social loafing during preparation for performance situations. Social Psychology, 43(1), 1-7.

Ones, D. S., Viswesvaran, C. ve Reiss, A. D. (1996). Role of social desirability in personality testing for personnel selection: The red herring. Journal of Applied Psychology, 81, 660-679. https://doi. org/10.1037/0021-9010.81.6.660

Pagda, Z., Bayraktar, S. ve Jimenez, A. (2021). Exploring culture and leadership after 23 years: A replication of GLOBE project in Turkey. Journal of International Management, 27(1), 100822. https://doi.org/10.1016/j.intman.2021.100822

Schippers, M. C. (2014). Social loafing tendencies and team performance: The compensating effect of agreeableness and conscientiousness. Academy of Management Learning \& Education, 13(1), 62-81. https://doi.org/10.5465/amle.2012.0191

Schnake, M. E. (1991). Equity in effort: The" sucker effect" in co-acting groups. Journal of Management, 17(1), 41-55. https://doi.org/10.1177/014920639101700104

Sezer, U. ve Kocaekşi, S. (2018). Genç Sporcu Takım Sargınlığı ölçeğinin (GSTSÖ) psikometrik özellikleri: Geçerlik ve güvenirlik çalışması. Spor Bilimleri Dergisi, 29(3), 105-113. https://doi. org/10.17644/sbd.345936

Sezer, U., Kocaekşi S., Taş̧̧ığlu, R., Özbal, F. ve Heper, E. (2020) Psychometric Properties of the Turkish Form of the Observational Collective Efficacy Scale for Sports. Acta Gymnica, 50(2), 7782. https://doi.org/10.5507/ag.2020.007

Shepperd, J. A. (1993). Productivity loss in performance groups: A motivation analysis. Psychological Bulletin, 113(1), 67-81. https://doi.org/10.1037/0033-2909.113.1.67

Singer, R. N. ve Orbach, I. (1999) Persistence, excellence, and fulfillment. R. Lidor ve M. Bar-Eli (Ed.), Sport psychology: Linking theory and practice içinde (s. 167-191). Morgantown: Bookcrafters

Steiger, J. H. (1990). Structural model evaluation and modification: An interval estimation approach. Multivariate Behavioral Research, 25, 214-12. https://doi.org/10.1207/s15327906mbr2502_4

Swain, A. (1996). Social loafing and identifiability: The mediating role of achievement goal orientations. 
Research Quarterly for Exercise and Sport, 67(3), 337-344. https://doi.org/10.1080/02701367.19 96.10607961

Tabachnick, B. G. ve Fidell, L. S. (2007). Using multivariate statistics (5. bs). Boston: Pearson Education Inc.

Tolukan, E., Bayrak, M. ve Karacan Doğan, P. (2017). Antrenörlerin sosyal kaytarma algılarının incelenmesi. Gaziantep Üniversitesi Spor bilimleri Dergisi, 2(1), 1-13.

Triandis, H. C. (2001). Individualism-Collectivism and personality. Journal of Personality, 69(6), 907924. https://doi.org/10.1111/1467-6494.696169

Tschan, F., Semmer, N. K., Nägele, C. ve Gurtner, A. (2000). Task adaptive behavior and performance in groups. Group Processes \& Intergroup Relations, 3(4), 367-386. https://doi. org/10.1177/1368430200003004003

Williams, K., Harkins, S. ve Latané, B. (1981). Identifiability as a deterrent to social loafing: Two cheering experiments. Journal of Personality and Social Psychology, 40, 303-311. https://doi. org/10.1037/0022-3514.40.2.303

Vaartstra, M., Dunn, J. G. H. ve Causgrove Dunn, J. (2018). Perfectionism and perceptions of social loafing in competitive youth soccer. Journal of Sport Behavior, 41, 475-500.

Vroom, V. H. (1964). Work and motivation. Oxford, England: Wiley.

Yetim, U. (2003). The impacts of individualism/collectivism, self-esteem, and feeling of mastery on life satisfaction among the Turkish university students and academicians. Social Indicators Research, 61(3), 297-317.

Ying, X., Li, H., Jiang, S., Peng, F. ve Lin, Z. (2014). Group laziness: The effect of social loafing on group performance. Social Behavior and Personality: An International Journal, 42(3), 465-471. https://doi.org/10.2224/sbp.2014.42.3.465

Yuki, M. (2003). Intergroup comparison versus intragroup cooperation: A cross-cultural examination of social identity theory in North American and East Asian cultural contexts. Social Psychology Quarterly, 66, 166-183. 
Ek 1. Algılanan Sosyal Kaytarma Ölçeği

\begin{tabular}{|c|c|c|c|c|}
\hline 1 & 2 & 3 & 4 & 5 \\
\hline Hiç Katılmıyorum & Kismen Katılmiyorum & $\begin{array}{l}\text { Ne Katıliyorum } \\
\text { Ne Katılmiyorum }\end{array}$ & Kismen Katıliyorum & Tamamen Katıliyorum \\
\hline
\end{tabular}

$\mathrm{Bu}$ ölçeğin kullanım amacı, sporcunun, takım içindeki diğer üyelerin göstermiş olduğu sosyal kaytarma davranışlarına yönelik algısını ölçmektir. Lütfen takım arkadaşlarınızı düşünerek aşağıdaki maddelere katılım düzeyinizi 1-5 arasında olacak şekilde işaretleyiniz.

1. Takım arkadaşlarım yapabileceklerinin en iyisini yapmaya çalışırlar.*

2. Takım arkadaşlarım başkalarının sırtından geçinen kişilerdir.

3. Takım arkadaşlarım takıma beklediğimden daha az katkıda bulunurlar.

4. Takım arkadaşlarım yetenekleri ölçüsünde yapabileceklerinin en iyisini yaparlar.*

5. Takım arkadaşlarım "başkalarının arkasına saklanırlar”, böylece daha fazla çaba harcamaya gerek duymazlar. $\begin{array}{lllll}1 & 2 & 3 & 4 & 5\end{array}$

$\begin{array}{lllll}1 & 2 & 3 & 4 & 5\end{array}$

$\begin{array}{lllll}1 & 2 & 3 & 4 & 5\end{array}$

$\begin{array}{lllll}1 & 2 & 3 & 4 & 5\end{array}$

$\begin{array}{lllll}1 & 2 & 3 & 4 & 5\end{array}$

* Ters puanlanan madde 